\title{
Systemic Blastomycosis Diagnosed by Prostate Needle Biopsy
}

Peter M. Neal, MD and Anne Nikolai, BS

\begin{abstract}
A healthy $5 \mathrm{I}$-year-old man presented with a I-month history of lower urinary tract irritative symptoms. Urinalysis was suggestive of infection, and the patient was treated with multiple antibiotics without relief of symptoms. A urological exam demonstrated abnormal induration of the prostate gland. Biopsy of the prostate gland revealed Blastomyces dermatitidis. In areas where Blastomyces dermatitidis is endemic, clinicians should be aware of the presence of this fungus and possible sites of infection.
\end{abstract}

Keywords: Blastomycosis; Blastomyces dermatitidis; Endemic disease; Genitourinary blastomycosis;

Mycotic disease, prostatic diagnosis; Prostatic blastomycosis

\author{
Reprint Requests: \\ Peter M. Neal, MD \\ Department of Urology \\ Marshfield Clinic Indianhead Center \\ 1020 Lakeshore Drive \\ Rice Lake, WI 54868 \\ Tel: $7|5-236-83| 3$ \\ Fax: 7|5-236-8|04 \\ Email: neal.peter@marshfieldclinic.org
}

Received: January 17, 2008

Revised: April I, 2008

Accepted: April 9, 2008

doi: $10.3121 / \mathrm{cmr} .2008 .789$
B

lastomycosis is a fungus endemic to the Great Lakes region of North America. It is typically found in areas of moist soil associated with organic content, as well as in watershed environments. Infection occurs in mammals, including humans and canines, usually by inhalation of germ spores. A pulmonary infection occurs, which may be subclinical and may become dormant. Alternately, the infection may disseminate by hematogenous or lymphatic spread to other sites such as skin, skeletal system or urinary tract. Pulmonary blastomycosis has the potential to run a severe, rapid and violent course including acute respiratory distress syndrome and death, even in young immunocompetent persons. This infection should not be underestimated. Rare primary cutaneous inoculation may occur. ${ }^{1-8}$

In North America, concentrations of cases of blastomycosis have occurred in the regions of the upper Great Lakes, the lower end of Lake Michigan, the St Lawrence, Ohio and Mississippi river valleys, and the southeast. ${ }^{2-6,8-12}$ As the annual incidence is uncommon (1 to 2 humans per 100,000), the disease is not required to be reported nationally. However, after recognizing two outbreaks in 1984, blastomycosis was designated a reportable disease in the state of Wisconsin. Total annual reported blastomycosis cases in Wisconsin ranged from 104 in 2002 to 169 in 2006, with a nadir of 82 cases in 2003. The disease is also currently reportable in the states of Mississippi and Illinois. Mississippi reported a total of 39 cases from 2002 through 2006 (personal communication, Theresa Kittle, Mississippi State Department of Health). Illinois reported a total of 743 cases from 1990 to 2004, although reporting has only been mandatory since 1994.5,13 Many Illinois cases are from the Chicago "collar" area in Cook, Lake and Kane counties. A similar cluster of cases has occurred in Milwaukee, Wisconsin. This may implicate urban watersheds as a source of infection. ${ }^{5,12}$

In high-risk areas of northern Wisconsin the incidence previously ranged from 10.4 to 41.4 annual cases per $100,0000^{2,3}$ Vilas County, WI has been the site of 3 major outbreaks of blastomycosis $1,14,15$ and reports human incidence as high as $100 / 100,000$ per year in the southeastern region of the county, inclusive of the city of Eagle River. ${ }^{16,17}$ Newer Wisconsin data from calendar year 2006 (figure 1) reports an even higher incidence in Lincoln County with 31 cases in 


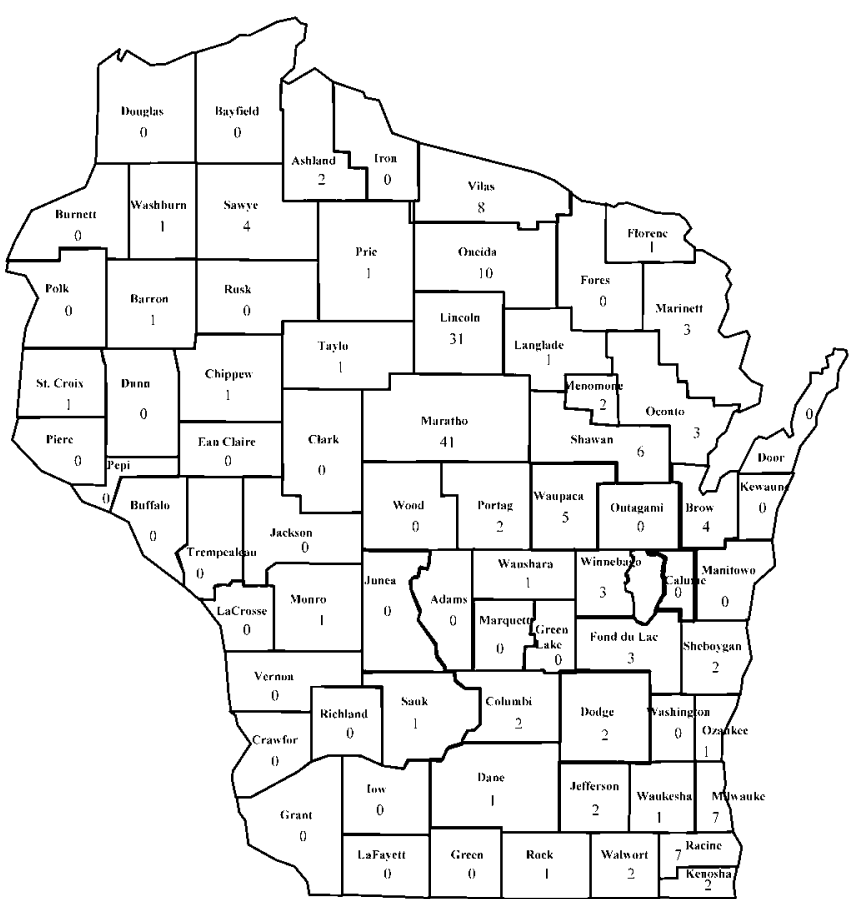

Figure 1. Blastomycosis cases by county in 2006. Of note, Vilas County reported a 2006 case count of 8 (rate 40.5), Marathon County reported 41 cases (rate of 32.2), and Oneida reported 10 cases (rate of 28.6).

a population of 29,142 resulting in an annual rate of 106.4 per 100,000 (personal communication, John Archer, Bureau of Communicable Disease, Wisconsin Division of Public Health). Clinicians should be aware of the presence of this fungus and possible sites of infection.

The fungi are indigenous to broad geographic regions worldwide (North America, India, Africa, South and Central America) but reproduce successfully in only a very specific "micro-niche."11 The innocuous spores are rarely isolated in nature but case analyses implicate decaying wood and podzolic soils with high organic content, possibly enriched with bird and animal feces, and formed under moist, cool and acidic conditions. This soil type is found near waterways under coniferous or boreal forests, as well as in warm sandy soils. Fluctuating water levels, a distinct change of seasons, and elevations of 30-600 $\mathrm{m}$ above sea level are also specified as contributing factors. Conditions of fog or recent rainfall may be present. ${ }^{2,11,18-20}$ Exposure occurs through excavation, construction, fishing, hunting and other soil-disturbing activities, and working with decaying wood. ${ }^{1,15,20}$ However, recent studies indicate that the majority of blastomycosis patients do not have specific outdoor occupations or recreational interests and may acquire the fungus in or near their homes. ${ }^{21-24}$

\section{Case Report}

A previously healthy 51-year-old male presented with a 1month history of urgency, frequency, dysuria and nocturia. The review of systems included a cough for the last 6 weeks. Past history was significant for rheumatoid arthritis, which was not currently being treated. He was not on any medications for this. The patient had no prior surgeries. He worked outdoor construction and smoked 1 pack of cigarettes a day.

A urinalysis demonstrated 10 to 12 white blood cells and 20 to 25 red blood cells. A urine culture was negative, however. The patient was treated with courses of cephalexin, doxycycline and levofloxacin. No resolution of symptoms occurred.

Urological physical examination showed normal phallus, testes and epididymi. The prostate gland was not tender, but was indurated along the right lateral border. His prostate specific antigen (PSA) was $0.87 \mathrm{ng}$ (males 50 to 59 years: normal 0.0 to $3.5 \mathrm{ng} / \mathrm{ml}$ [Marshfield Laboratories]). The patient underwent a standard transrectal, ultrasound-guided biopsy of the prostate, with attention to the suspicious area. Pathological examination revealed typical Blastomyces dermatitidis yeast forms (figures 2-4).

Further work-up included a negative renal ultrasound, a chest $\mathrm{x}$-ray that demonstrated hilar adenopathy, and computerized tomography (CT) lung imaging that revealed hilar and mediastinal adenopathy with bilateral perivascular and perilymphatic nodules in the upper lobes (figures 5 and 6). A bronchoscopy was performed. No abnormalities were visualized, and washings, smears and cultures were negative for bacteria, fungus and acid fast bacteria. A fine needle aspirate was done of the hilar nodes, which identified $B$. dermatitidis. Neither serological studies nor urinary antigen testing was performed on the patient.

The patient was treated with itraconazole for 6 months. He reported symptom improvement within 2 weeks of beginning treatment.

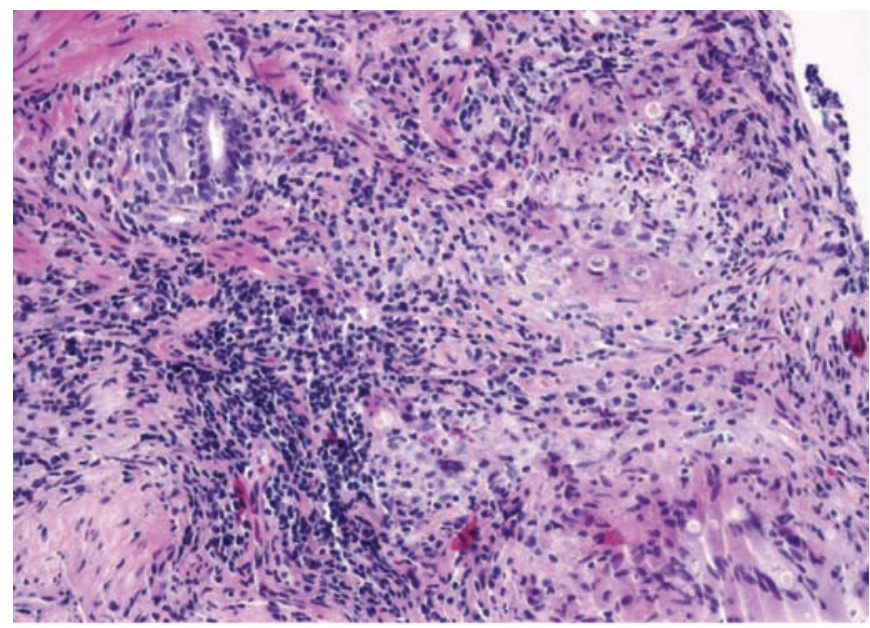

Figure 2. A prostatic acinus surrounded by granulomatous inflammation including Blastomyces organisms. The hematoxylin/eosin stain does not stain the capsule of the organisms. 


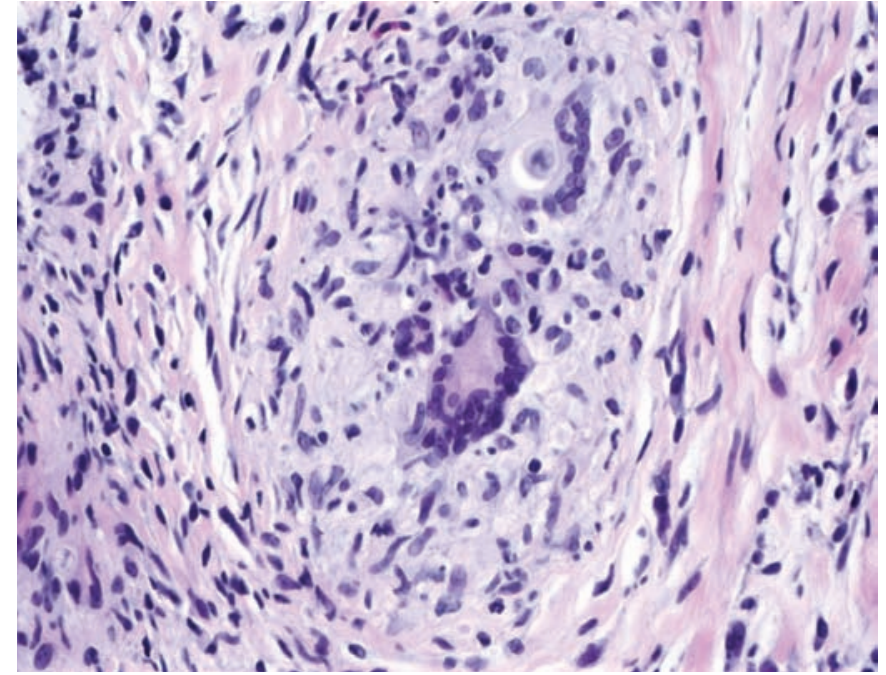

Figure 3. High magnification of the granulomatous inflammation with foreign body giant cells, macrophages, acute and chronic inflammation and Blastomyces organisms.

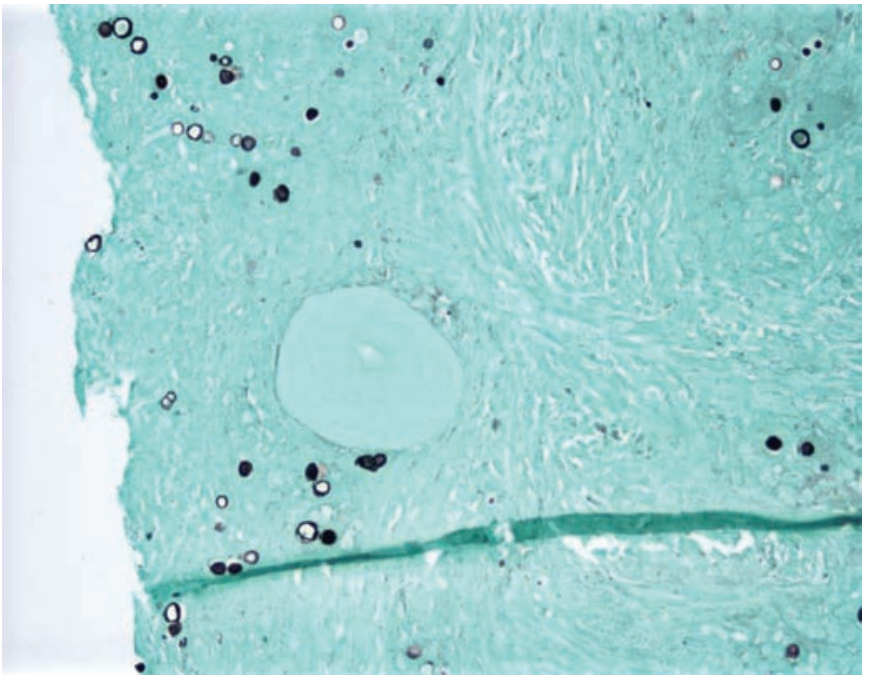

Figure 4. Methenamine silver stain showing the cell wall of the organisms. Note the broad based budding characteristic of Blastomyces.

\section{Discussion}

Patients infected with blastomycosis present about half the time with a flu-like illness, pulmonary symptoms, pneumonia (possibly failed antibiotic therapy), cough, hemoptysis, weight loss, pleuritic chest pain, myalgia, arthralgia and/or fever (low grade if present). The most common mistaken diagnoses include pneumonia, tuberculosis and neoplasm. ${ }^{5}$ Manifestations occur less commonly in skin, bone, genitourinary and central nervous systems, respectively, although any organ system may be involved. Subjects may experience different courses of the fungal infection. ${ }^{25}$

Diagnosis requires a high degree of suspicion. Serologic and skin tests are non-invasive and rapid but are limited by sensitivity and specificity. 2,4,5,26,27 Antigen detection in urine or other body fluids for $B$. dermatitidis is reported as sensitive with high reproducibility however cross reactivity with other mycoses may prohibit clear diagnosis. ${ }^{28-30}$ The WI-1 antigen based antibody test has good sensitivity and specificity but is not widely available. ${ }^{31}$ Antigen detection can be useful to monitor treatment efficacy in patients with disseminated blastomycosis. ${ }^{32,33}$ A fungal culture and stain obtaining 2 primary samples is recommended. For broad-based, large yeasts such as $B$. dermatitidis, fungal stain is more reliable than Gram's stain. Sample collection should include pulmonary secretions or tissue in an acute primary or chronic infection. A tissue biopsy should also be obtained in cases of secondary infection, and in these extrapulmonary cases the organisms are also visible on routine hematoxylin-eosin or Papanicolaou stains. 5,27,34 Chest radiography should be performed in every case of blastomycosis. ${ }^{2}$ An additional diagnostic challenge to the clinician may be that blastomycosis has an expanding yet fairly well-defined area of endemicity. ${ }^{31}$ However, due to a mobile population with more time for leisure activities, blastomycosis and other endemic fungi may present far from their endemic area of acquisition.

Fifteen to $30 \%$ of blastomycosis cases demonstrate genitourinary involvement. This may occur in the kidneys, adrenals, testes, epididymi, preputial skin and prostate. Most of these cases represent progression of systemic disease. ${ }^{34-36}$ Typical presentation of genitourinary disease includes dysuria, hesitancy, nocturia, urinary retention, urinary outlet obstruction, perineal or suprapubic discomfort, hematuria and hematospermia. ${ }^{35,37,38}$ Digital rectal examination may be useful in identifying a possible prostatic infection. ${ }^{39}$ Prostatic changes potentially caused by blastomycosis may mimic bacterial infection, benign prostatic hypertrophy or neoplasm. ${ }^{38}$ Pulmonary x-ray may be positive at this time. Diagnosis of genitourinary blastomycosis is based on a high index of suspicion and may be obtained from a urine culture and/or histological examination of affected tissue (prostate, penile skin, testes or epididymi). The finding of organisms in expressed prostatic excretions has been described. ${ }^{34}$ Antigen detection testing in urine expelled following prostatic massage may be sensitive. Serological studies are available but have not been found to be useful in definitive diagnosis. A case of conjugal transmission is reported in which a male was diagnosed with blastomycosis of the prostate and epididymis and the female was later diagnosed with blastomycosis infection of the endometrium and fallopian tubes. ${ }^{40}$

The current treatment of choice for blastomycosis is itraconazole. This is the oral agent that has replaced both ketoconazole and amphotericin deoxycholate, except for patients with central nervous system involvement and in cases of life-threatening infection when amphotericin B should be used. Liposomal amphotericin could also be used in the event of nephrotoxicity. ${ }^{27}$ Voriconazole appears promising targeting blastomycotic meningitis, with favorable pharmacokinetics, 

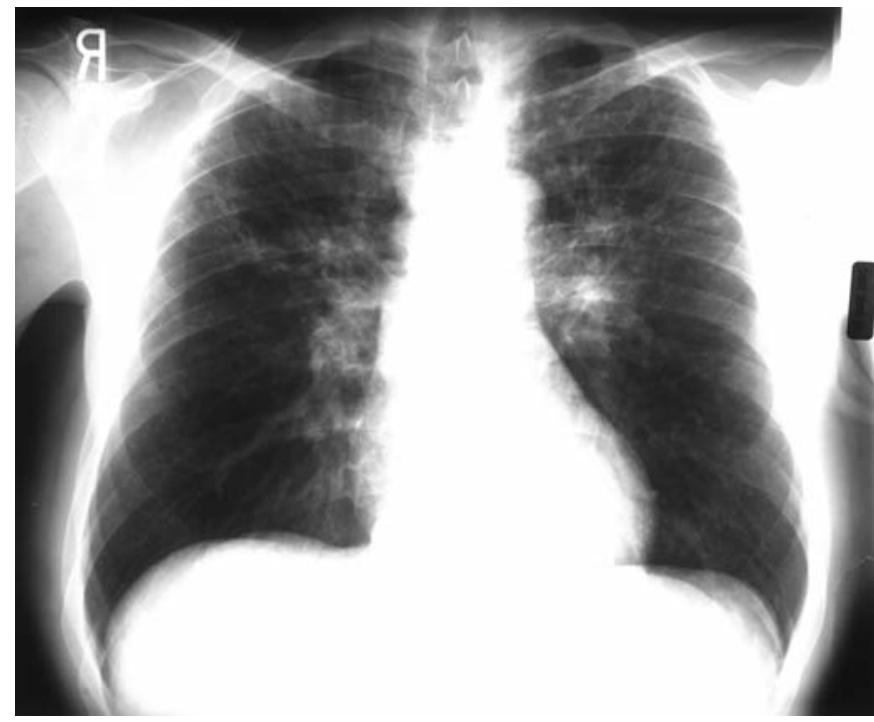

Figure 5. PA and Lateral chest x-ray shows mixed interstitial and nodular opacities throughout each upper lobe with superior retraction of each hila combined with mild pleural thickening at each apex; and suprahilar densities bilaterally which are somewhat confluent.

but remains unproven. Posaconazole is a newer agent pending complete elucidation as well. 2,4,41

\section{Conclusion}

B. dermatitidis is a common fungus in the Great Lakes region of North America. It may cause pulmonary infection after inhalation of germ spores. The typically pulmonary infection may be subclinical and may be followed by heterogeneous or lymphatic dissemination. In areas where blastomycosis is felt to be endemic, such as Wisconsin, clinicians should be aware of the presence of this fungus and possible sites of infection.

In the case we describe, an extensive pulmonary evaluation was performed after a biopsy of the prostate gland documented blastomycosis infection. Diagnosis of genitourinary blastomycosis is based on index of suspicion, history of exposure and physical findings. Confirmation of infection is made by pathologic examination of affected tissue or expressed prostatic secretions.

Serological studies are available but have not been found to be useful in definitive diagnosis. Typically blastomycosis can be treated successfully with readily available oral agents.

\section{Author's Note}

"Practice Guidelines for the Management of Patients with Blastomycosis" are currently under revision by the Infectious Diseases Society of America and scheduled for release late 2008. For more information, visit http://www.idsociety.org/Content.aspx?id=2656.

\section{Acknowledgments}

The authors thank Marshfield Clinic Research Foundation for its support through the assistance of Alice Stargardt and Linda Weis in the preparation of this manuscript.

\section{References}

1. Klein BS, Vergeront JM, Davis JP. Epidemiologic aspects of blastomycosis, the enigmatic systemic mycosis. Semin Respir Infect 1986;1:29-39.

2. Bradsher RW, Chapman SW, Pappas PG. Blastomycosis. Infect Dis Clin North Am 2003;17:21-40, vii.

3. Centers for Disease Control and Prevention (CDC). Blastomycosis - Wisconsin, 1986-1995. MMWR Morb Mortal Wkly Rep 1996;45:601-603.

4. Sarosi GA. Fungal infections and their treatment in the intensive care unit. Curr Opin Crit Care 2006;12:464-469.

5. Taxy JB. Blastomycosis: contributions of morphology to diagnosis: a surgical pathology, cytopathology, and autopsy pathology study. Am J Surg Pathol 2007;31:615-623.

6. Centers for Disease Control and Prevention Web site. Division of Bacterial and Mycotic Diseases: Blastomycosis. Available at: http://www.cdc.gov/ncidod/dbmd/diseaseinfo/blastomycosis_t .htm. Accessed July 18, 2007.

7. Witorsch P, Utz JP. North American blastomycosis: a study of 40 patients. Medicine (Baltimore) 1968;47:169-200.

8. Meyer KC, McManus EJ, Maki DG. Overwhelming pulmonary blastomycosis associated with the adult respiratory distress syndrome. New Engl J Med 1993; 329:1231-6.

9. Klein BS, Davis JP. A laboratory-based surveillance of human blastomycosis in Wisconsin between 1973 and 1982. Am J Epidemiol 1985;122:897-903

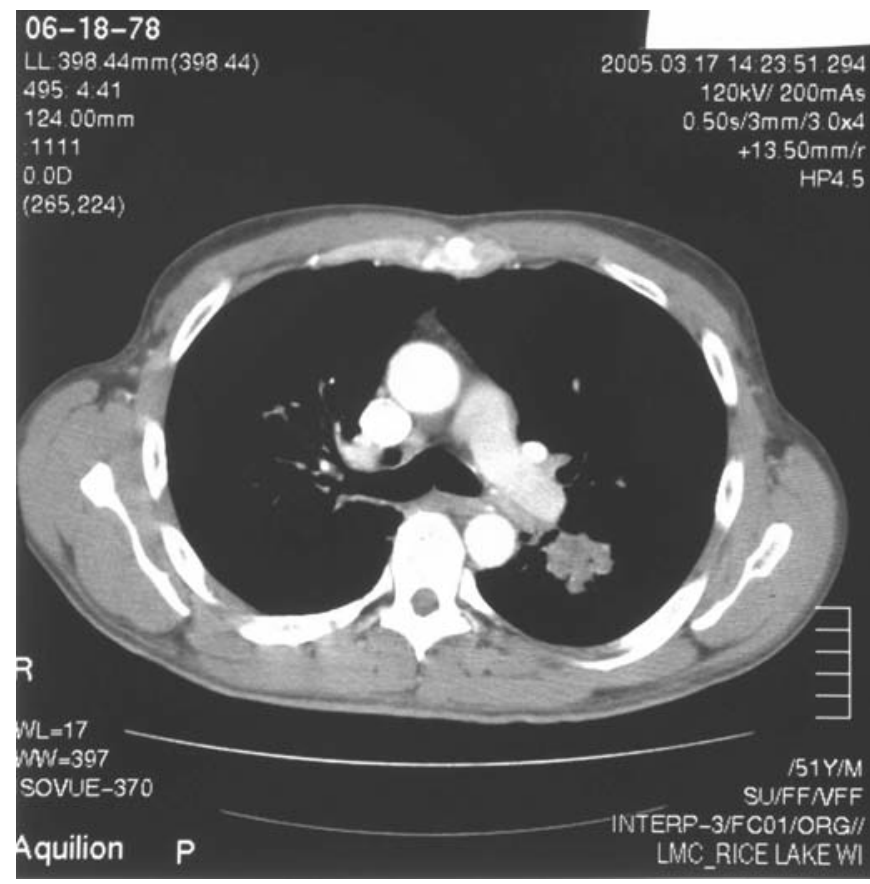

Figure 6. Spiral chest CT with intravenous contrast bolus shows significant bilateral perihilar lymphadenopathy; numerous perivascular and perilymphatic nodular densities somewhat irregular in contour; scattered subpleural nodules; mild to moderate mediastinal adenopathy; small axillary lymph nodes present bilaterally; and a prominent left perihilar mass contiguous with hilar adenopathy. 
10. Stephens J. Cutaneous blastomycosis in the absence of active pulmonary disease. J Am Acad Dermatol 2007;56:AB130.

11. Baumgardner DJ, Steber D, Glazier R, Paretsky DP, Egan G, Baumgardner AM, Prigge D. Geographic information system analysis of blastomycosis in northern Wisconsin, USA: waterways and soil. Med Mycol 2005;43:117-125.

12. Baumgardner DJ, Knavel EM, Steber D, Swain GR. Geographic distribution of human blastomycosis cases in Milwaukee, Wisconsin, USA: association with urban watersheds. Mycopathologia 2006;161:275-282.

13. Illinois Department of Public Health Web site. Reportable Communicable Disease Cases, 2000 - 2006. Available at: http://www.idph.state.il.us/health/infect/communicabledisease 00_09.htm. Accessed July 23, 2007.

14. Baumgardner DJ, Burdick JS. An outbreak of human and canine blastomycosis. Rev Infect Dis 1991;13:898-905.

15. Baumgardner DJ, Egan G, Giles S, Laundre B. An outbreak of blastomycosis on a United States Indian reservation. Wilderness Environ Med 2002;13:250-252.

16. Baumgardner DJ, Buggy BP, Mattson BJ, Burdick JS, Ludwig D. Epidemiology of blastomycosis in a region of high endemicity in north central Wisconsin. Clin Infect Dis 1992;15:629-635.

17. Baumgardner DJ, Brockman K. Epidemiology of human blastomycosis in Vilas County, Wisconsin. II: 1991-1996. WMJ 1998;97:44-47.

18. Klein BS, Vergeront JM, DiSalvo AF, Kaufman L, Davis JP. Two outbreaks of blastomycosis along rivers in Wisconsin. Isolation of $B$. dermatitidis from riverbank soil and evidence of its transmission along waterways. Am Rev Respir Dis 1987;136:1333-1338.

19. Burgess JW, Schwan WR, Volk TJ. PCR-based detection of DNA from the human pathogen Blastomyces dermatitidis from natural soil samples. Med Mycol 2006;44:741-748.

20. Wisconsin Department of Health \& Family Services Web site. WISCONSIN EPI EXPRESS, April 29, 2004. Available at: http://dhfs.wisconsin.gov/communicable/EpiExpress/pdf/WE E04-29-04.pdf. Accessed July 19, 2007.

21. Blondin N, Baumgardner DJ, Moore GE, Glickman LT. Blastomycosis in indoor cats: suburban Chicago, Illinois, USA. Mycopathologia 2007; 163(2):59-66.

22. Chapman SW, Lin AC, Hendricks KA, Nolan RL, Currier MM, Morris KR, Turner HR Endemic blastomycosis in Mississippi: epidemiological and clinic studies. Semin Respir Infect 1997; 12(3): 219-28

23. Vasquez JE, Meha JB, Agrawal R, Sarubbi FA. Blastomycosis in northeast Tennessee. Chest 1998; 114(2): 436-443.

24. Cano MV, Ponce-de-Leon GF, Tippen S, Lindsley MD, Warwick M, Hajjeh RA. Blastomycosis in Missouri: epidemiology and risk factors for endemic disease. Epidemiol. Infect. 2003; 131(2): 907-914.

25. Baumgardner DJ, Halsmer SE, Egan G. Symptoms of pulmonary blastomycosis: northern Wisconsin, United States. Wilderness Environ Med 2004;15:250-256.

26. Hurst SF, Kaufman L. Western immunoblot analysis and serologic characterization of Blastomyces dermatitidis yeast form extracellular antigens. J Clin Microbiol. 1992; 30(12):3043-9.

27. Chapman SW, Bradsher RW Jr, Campbell GD Jr, Pappas PG, Kauffman CA.

Guidelines From The Infectious Diseases Society Of America Practice Guidelines For The Management Of Patients With Blastomycosis.

Clin Infect Dis. 2000;30;679-83. Epub 2000 Apr 20.

28. Bradsher RW, Chapman SW, Pappas PG. Blastomycosis. Infect Dis Clin North Am. 2003;17:21-40.
29. Durkin M, Witt J, Lemonte A, Wheat B, Connolly P. Antigen assay with the potential to aid in diagnosis of blastomycosis. J Clin Microbiol. 2004;42(10):4873-5.

30. Shurley JF, Legendre AM, Scalarone GM Blastomyces dermatitidis antigen detection in urine specimens from dogs with blastomycosis using a competitive binding inhibition ELISA. Mycopathologia. 2005;160(2):137-42.

31. Blastomycosis acquired occupationally during prairie dog relocation - Colorado, 1998. MMWR 1999;48(05): 98-100.

32. Tarr M, Marcinak J, Mongkolrattanothai K, Burns JL, Wheat LJ, Durkin M, Ismail M. Blastomyces antigen detection for monitoring progression of blastomycosis in a pregnant adolescent. Infect Dis Obstet Gynecol. 2007;2007:89059.

33. Mongkolrattanothai K, Peev M, Wheat LJ, Marcinak J Urine antigen detection of blastomycosis in pediatric patients Pediatr Infect Dis J. 2006:25(11);1076-8.

34. Eickenberg H-U, Amin M, Lich R. Blastomycosis of the genitourinary tract. J Urol 1975;113:650-652.

35. Inoshita T, Youngberg GA, Boelen LJ, Langston J. Blastomycosis presenting with prostatic involvement: report of 2 cases and review of the literature. J Urol 1983; 130:160-162.

36. Seo R, Oyasu R, Schaeffer A. Blastomycosis of the epididymis and prostate. Urology 1997;50:980-982.

37. Bissada NK, Finkbeiner AE, Redman JF. Prostatic mycosis: nonsurgical diagnosis and management. Urology 1977; 9:327-328.

38. Wise GJ, Shteynshlyuger A. How to diagnose and treat fungal infections in chronic prostatitis. Curr Urol Rep 2006; 7:320328 .

39. Watts B, Argekar P, Saint S, Kauffman CA. Clinical problemsolving. Building a diagnosis from the ground up - a 49year-old man came to the clinic with a 1-week history of suprapubic pain and fever. N Engl J Med 2007; 356:1456-1462.

40. Craig MW, Davey WN, Green RA. Conjugal blastomycosis. Am Rev Respir Dis 1970;102:86-90.

41. Enoch DA, Ludlam HA, Brown NM. Invasive fungal infections: a review of epidemiology And Management Options. J Med Microbiol 2006;55:809:818.

\section{Author Affiliations}

Peter M. Neal, MD

Department of Urology

Marshfield Clinic Indianhead Center

1020 Lakeshore Drive

Rice Lake, Wisconsin 54868

Anne Nikolai, BS

Clinical Research Center

Marshfield Clinic Research Foundation

1000 North Oak Avenue

Marshfield, Wisconsin 54449 